\title{
LOCALIZATION OF LEUCINE AMINOPEPTIDASE IN SERUM AND BODY FLUIDS BY STARCH GEL ELECTROPHORESIS *
}

\author{
By O. DHODANAND KOWLESSAR, LORRAINE J. HAEFFNER AND \\ MARVIN H. SLEISENGER
}

(From the Department of Medicine, New York Hospital-Cornell Medical Center, New York, N.Y.)

(Submitted for publication October 9, 1959; accepted December 10, 1959)

Serum leucine aminopeptidase (LAP), as measured by the method of Goldbarg and Rutenburg (1), is elevated in patients with biliary cirrhosis, intrahepatic cholestasis, metastatic carcinoma of the liver, carcinoma of the pancreas obstructing the common bile duct or metastatic to the liver, carcinoma of the biliary tree, primary hepatoma, infiltrative diseases of the liver such as lymphoma, sarcoidosis, and so forth, and infectious hepatitis $(2,3)$.

In order further to compare serum LAP activity in normal subjects and in patients with a variety of diseases involving the pancreas, liver and biliary tree, its mobility was measured by starch gel electrophoresis. Although there was a common peak of activity in the sera of both normal subjects and of patients with the diseases studied, LAP was also noted at other sites in the latter group.

\section{MATERIALS AND METHODS}

All sera were obtained from fasting, normal healthy subjects and from patients on the medical and surgical wards of The New York Hospital, whose diagnoses were confirmed either by biopsy, surgical exploration, autopsy, or by their clinical courses.

The study group included 8 normal adults and 36 patients with a variety of inflammatory, malignant, and granulomatous diseases affecting the liver, biliary tract, and/or the pancreas. There were 6 patients with primary biliary cirrhosis; 6 with acute infectious hepatitis; 5 with Laennec's cirrhosis and acute fatty infiltration of the liver; 1 with lymphosarcoma involving the liver; 1 with sarcoidosis; 2 with Hodgkin's disease; 4 with carcinoma of the colon, metastatic to the liver; 2 with common duct stone; 1 with toxic hepatitis secondary to Mitomycin; and 1 with infectious mononucleosis. Seven patients with carcinoma of the pancreas were also studied (Table I). In 6 the tumor was in the head of the pancreas. Of these, 2 had obstruction of the common

* This work was supported by Research Grant CS9386 from the National Institutes of Health, Bethesda, Md. bile duct but no metastases to the liver; 2 had no obstruction but had hepatic metastases; and 2 had neither obstruction nor metastases. One patient's lesion was in the body and tail of the pancreas but was metastatic to the liver. This individual, however, had no common duct obstruction.

All of the patients had elevated levels of serum LAP, except the two with carcinoma of the head of the pancreas with neither common duct obstruction nor metastases to the liver. Three patients with viral hepatitis and two with cirrhosis and fatty infiltration were studied serially and upon recovery, when the elevated serum LAP had fallen to normal.

Serum proteins were separated by zone electrophoresis according to a modification of the starch gel method of Smithies (4), reported by Pert, Sleisenger, Woods and Engle (5). Electrophoresis was carried out at $12^{\circ}$ $\mathrm{C}$ at $4.5 \mathrm{v}$ per $\mathrm{cm}$ for 16 hours. In early experiments electrophoresis was performed using starch gel strips $2 \mathrm{~cm}$ wide. After completion of the electrophoretic run, the gels were scored in $0.5 \mathrm{~cm}$ sections and cut in half along the horizontal plane. One half was retained for protein staining with a saturated solution of naphthalene black 12B $200(4)$, and the second half was cut in 0.5 $\mathrm{cm}$ sections which were placed directly in tubes containing the necessary amount of buffered substrate for the determination of LAP by the method of Goldbarg and Rutenburg, at $\mathrm{pH} 7.1$ utilizing a chromogenic substrate, L-leucyl- $\beta$-naphthylamide hydrochloride. The $\beta$-naphthylamine liberated by enzymatic hydrolysis was assayed by a modified Bratton-Marshall reaction (1). Activity under each major peak was expressed as percentage of the sum total of all $0.5 \mathrm{~cm}$ sections of the gel strips (Table I).

In later experiments, when information was needed regarding the amount of protein present in each $0.5 \mathrm{~cm}$ section, starch gel strips, $4.5 \mathrm{~cm}$ wide, were used. The serum protein was separated by zone electrophoresis in a similar manner. The strips were scored in $0.5 \mathrm{~cm}$ sections but were divided in half vertically before being halved along the horizontal plane. One-fourth of the gel was retained for protein staining. In the remaining three-fourths, corresponding $0.5 \mathrm{~cm}$ sections of the gel were placed in separate tubes containing $3 \mathrm{ml}$ of water, mechanically shanis for 30 minutes at room temperature, and eluates of each $0.5 \mathrm{~cm}$ section were recovered. The eluates were then filtered and $0.2 \mathrm{ml}$ of the filtrate was assayed for protein by the micromethod of Lowry, 
TABLE I

Electrophoretic distribution of leucine aminopeptidase (LAP) in serum and body fluids

\begin{tabular}{|c|c|c|c|c|c|}
\hline \multirow[b]{2}{*}{ Diagnosis } & \multirow[b]{2}{*}{ No. studied } & \multirow[b]{2}{*}{$\begin{array}{l}\text { No. of peaks } \\
\text { of LAP found }\end{array}$} & \multicolumn{3}{|c|}{$\begin{array}{l}\text { Mean \% activity and standard deviation of } \\
\text { mean in each peak* }\end{array}$} \\
\hline & & & $\begin{array}{l}\text { Postalbumin } \\
\text { or fast } \alpha_{2} \text { to } \\
\text { postalbumin }\end{array}$ & $\begin{array}{l}\text { Origin to } \\
\text { slow } \alpha_{2}\end{array}$ & $\underset{\beta \text {-globulin }}{\alpha_{2} \text { to }}$ \\
\hline Normal subjects & 8 & 1 & $67.5 \pm 2.2$ & 0 & 0 \\
\hline Biliary cirrhosis & 6 & 2 & $68.0 \pm 1.4$ & $11 \pm 2.0$ & 0 \\
\hline $\begin{array}{l}\text { Toxic hepatitis secondary } \\
\text { to Mitomycin }\end{array}$ & 1 & 2 & 55.0 & 30 & 0 \\
\hline Acute infectious hepatitis & 6 & 3 & $57.0 \pm 2.5$ & $9.5 \pm 1.0$ & $14 \pm 0.5$ \\
\hline $\begin{array}{l}\text { Infectious hepatitis } \\
\text { (recovered) }\end{array}$ & 3 & 1 & $66.0 \pm 3.4$ & 0 & 0 \\
\hline $\begin{array}{l}\text { Laennec's cirrhosis with } \\
\text { acute fatty infiltration }\end{array}$ & 5 & 3 & $58.0 \pm 1.8$ & $8 \pm 0.4$ & $20 \pm 0.6$ \\
\hline $\begin{array}{l}\text { Laennec's cirrhosis after } \\
\text { recovery }\end{array}$ & 2 & 1 & 68.0 & 0 & 0 \\
\hline Lymphoma & 1 & 3 & 68.0 & 5 & 14 \\
\hline Hodgkin's disease & 2 & 3 & 70.0 & 5 & 12 \\
\hline Sarcoidosis & 1 & 3 & 67.0 & 5 & 14 \\
\hline Common duct stone & 2 & 3 & 45.0 & 15 & 15 \\
\hline $\begin{array}{l}\text { Carcinoma pancreas with } \\
\text { elevated LAP† }\end{array}$ & 5 & 3 & $48.0 \pm 0.4$ & $15 \pm 0.5$ & $15 \pm 1.2$ \\
\hline $\begin{array}{l}\text { Carcinoma of head of } \\
\text { pancreas with normal } \\
\text { LAP } \ddagger\end{array}$ & 2 & 1 & 65.0 & 0 & 0 \\
\hline $\begin{array}{l}\text { Metastatic carcinoma to } \\
\text { liver }\end{array}$ & 4 & 3 & $45.0 \pm 2.1$ & $15 \pm 1.1$ & $12 \pm 1.3$ \\
\hline Infectious mononucleosis & 1 & 3 & 45 & 12 & 20 \\
\hline Bile & 3 & 1 & $80 \pm 1 \S$ & 0 & 0 \\
\hline Ascitic fluid & 1 & 1 & $80 \S$ & 0 & 0 \\
\hline Pleural fluid & 1 & 1 & $82 \S$ & 0 & 0 \\
\hline
\end{tabular}

* Mean per cent and standard deviation of the mean per cent when more than two specimens were studied. † Tumors had either obstructed common bile duct or metastasized to liver. $\ddagger$ Tumors neither obstructed common duct nor metastasized to liver. $\S$ Specimens were diluted 1:1 with normal serum.

Rosebrough, Farr and Randall (6), and compared with a bovine albumin standard. One $\mathrm{ml}$ of the filtrate was used for the determination of LAP.

LAP activity is plotted against the distances per $0.5 \mathrm{~cm}$ migrated (cross-hatched bars; Figures 1-3, 6). Protein concentrations of the filtered eluate are similarly plotted for each $0.5 \mathrm{~cm}$ section (open bars; Figures 4,5 ). In all figures, except $B$ in Figure 1, electrophoregrams are placed on the abscissa to locate peak LAP activity in terms of the component protein fractions.

Similarly, electrophoresis, protein assays, and LAP determinations were performed on specimens of ascitic fluid, pleural fluid, bile obtained from patients by T-tube drainage of the common duct and by peroral duodenal intubation, 1 per cent pancreatic extract (Organon), and mixtures of the latter two substances with normal and abnormal sera.

\section{RESULTS}

The starch gel electrophoretic patterns showed that in all instances the major zone of LAP activity coincided exactly with the postalbumin fraction of serum or lay in the region of the fast $\alpha_{2}$ and postalbumin fractions. In 34 pathological sera there was significant activity in the region between the origin and slow $\alpha_{2}$, and in 27 of these specimens a peak of activity was also found in the region of the slow $\alpha_{2}$ and $\beta$-globulin fractions. The area labeled origin to slow $\alpha_{2}$ does not stain with the protein stain used in our experiments, but it can be seen that there is a large amount of protein present as measured by the microprotein determination (Figures 4, 5). 
Table I summarizes the results obtained from 54 specimens and includes the diagnosis, the nature of specimen studied, the number of peaks of LAP found and the activity of each peak expressed as percentage of the sum total of all 0.5 $\mathrm{cm}$ sections of the gel.

Normal subjects. In the sera of all eight normal subjects, there was one peak of LAP activity. In six specimens this peak coincided exactly with the postalbumin fraction of serum, but in two instances it lay in the region of the fast $\alpha_{2}$ and postalbumin (Figure 1). In no instance was any other peak of LAP activity found, even though there was measurable activity in several segments of the gel. No LAP activity was present in the gamma globulin and albumin fractions.

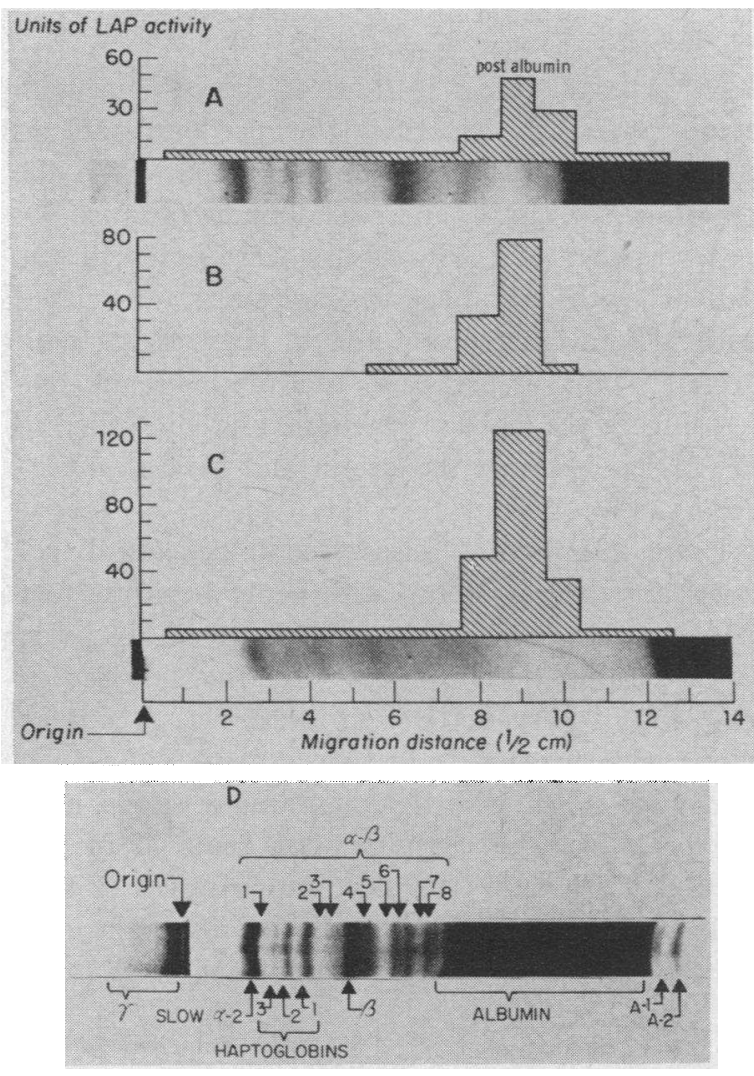

Fig. 1. Localization of LeUcine aminopeptidase (LAP) BY STARCH GEL ELECTROPHORESIS, DEMONSTRATING PEAKS of enzyme ACtivity. A. Normal serum. B. Bile. C. Bile and normal serum mixture $(1: 1)$. A stained electrophoregram was not obtained when bile was electrophoresed, due to the small amount of protein present in bile. D. Starch gel electrophoregram of normal serum for reference. In $\alpha-\beta$ complex, fraction $6=$ fast $\alpha_{2}$, and fractions 7 and $8=$ postalbumin.

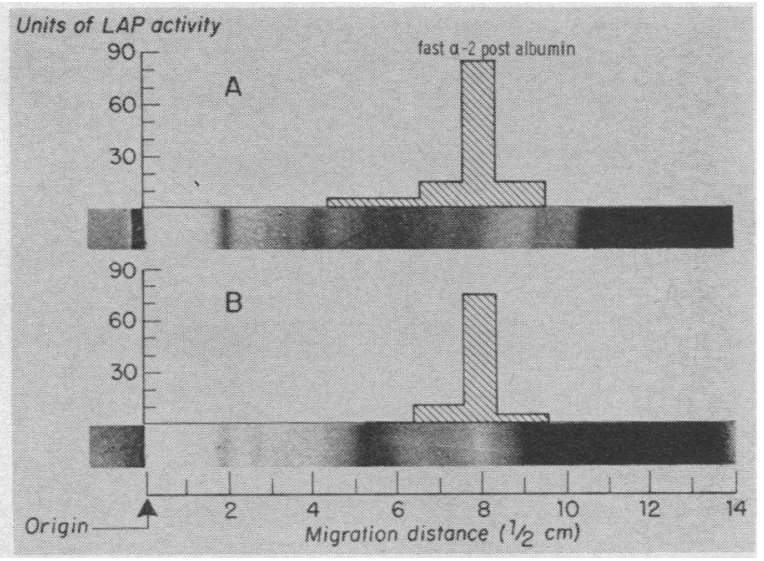

Fig. 2. Localization of LAP IN BODY FLUids BY STARCH GEL ELECTROPHORESIS. A. Ascitic fluid from a patient with Laennec's cirrhosis. B. Pleural fluid from a patient with carcinoma of the lung.

Biological fluids. Bile, obtained from both choledochostomy drainage and peroral duodenal intubation, pleural fluid, ascitic fluid, and pancreatic extract (Organon) run separately or diluted $1: 1$ with normal sera, also demonstrated only one peak of LAP activity, coinciding with the postalbumin fraction or the fast $\alpha_{2}$ and postalbumin (Figures 1,2). When these fluids were diluted with sera having elevated LAP activity, all peaks of LAP activity were preserved and the postalbumin peak or the peak coinciding with the fast $\alpha_{2}$ and postalbumin was augmented.

Pathological sera. In all six cases of acute infectious hepatitis, three peaks of LAP activity were found. An average of 57 per cent of the total enzyme activity either coincided with the

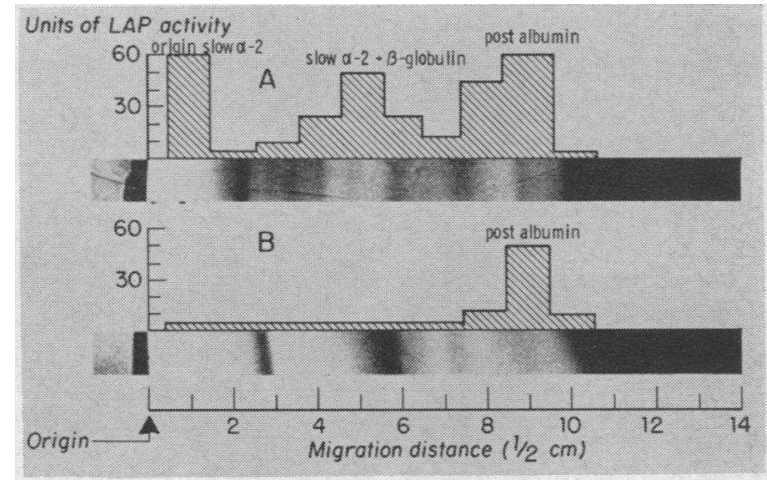

Fig. 3. Localization of SERUM LAP in INFECTIOUS hepatitis. A. During acute phase of disease-third day. B. During recovery, when serum LAP and liver biopsy were normal. 


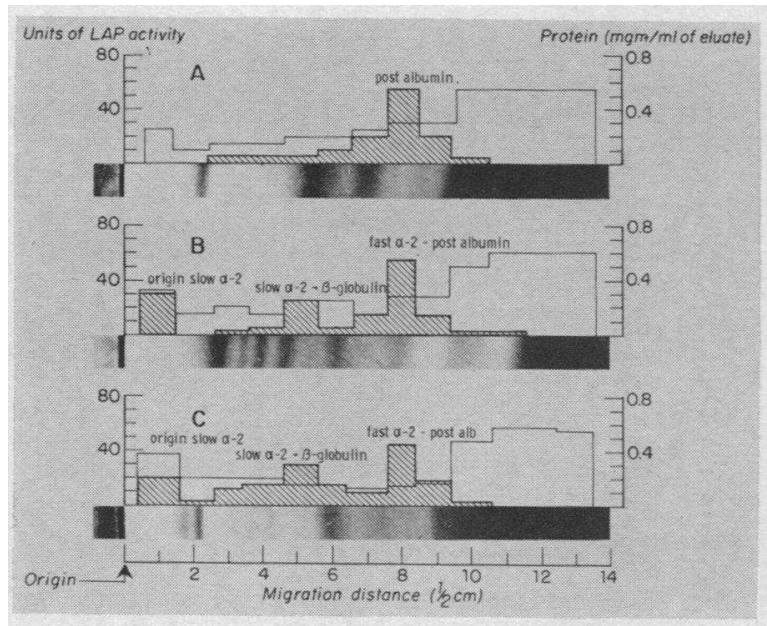

Fig. 4. Localization of SERUM LAP in carcinoma. A. Patient with carcinoma of the pancreas with normal serum LAP. B. Patient with carcinoma of the pancreas metastatic to the liver with elevated serum LAP. C. Patient with carcinoma of the cecum metastatic to the liver. Open bar = protein (milligrams per milliliter of eluate). Hatched bar = units of LAP activity.

postalbumin fraction or was in its immediate vicinity. The average activity in the origin and slow $\alpha_{2}$ fraction and in the region of slow $\alpha_{2}$ and $\beta$-globulin fractions was 9.5 and 14 per cent, respectively (Figure 3 ). Infiltrative diseases of the liver, i.e., sarcoidosis, lymphosarcoma, and Hodgkin's disease, carcinoma of the pancreas with obstruction of the common bile duct or metastatic to the liver and elevated serum LAP; common bile duct stone; Laennec's cirrhosis with acute fatty infiltration; and metastatic carcinoma of the liver all consistently showed three peaks of

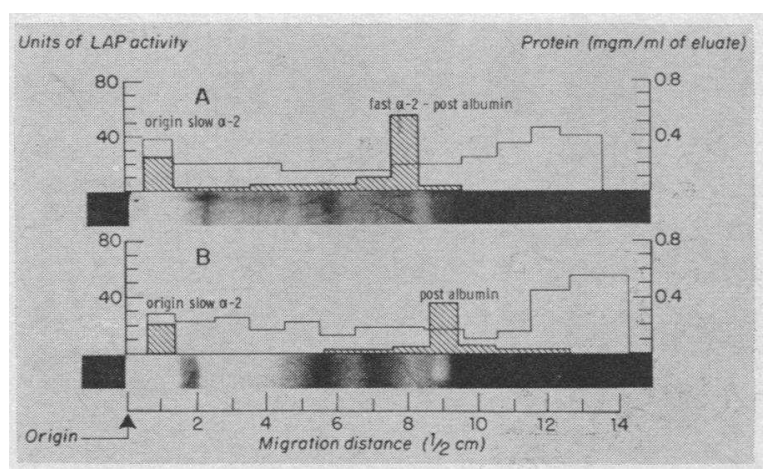

Fig. 5. LOCALIZATION OF SERUM LAP IN INTRAhepatic Cholestasis. A. Patient with biliary cirrhosis. B. Patient with cholangiolitic hepatitis secondary to Mitomycin.

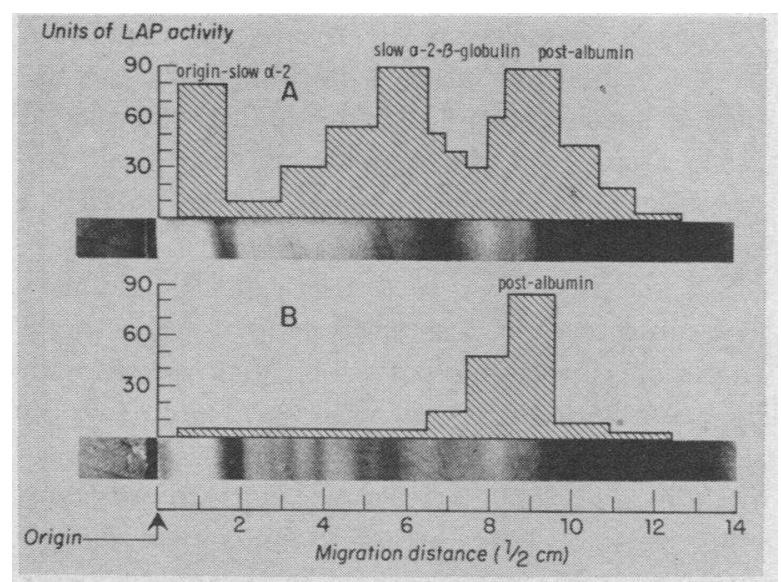

Fig. 6. Localization of SERUM LAP in COMMON BILE DUCt obstruction. A. Patient with common bile duct stone. B. Thirty days after surgical relief of the obstruction.

LAP activity similar to those in the patients with acute infectious hepatitis, the predominant activity lying in the postalbumin fraction or in the region of the fast $\alpha_{2}$ and postalbumin (Figure 4).

Two peaks of LAP activity were noted in one patient with intrahepatic cholestasis associated with Mitomycin therapy and in six patients with primary biliary cirrhosis, the predominant one residing in the normal fractions and the other in the region between the origin and slow $\alpha_{2}$ (Figure 5).

Upon complete clinical and biochemical recovery of three patients with acute hepatitis and of two patients with fatty infiltration of the liver, repeat studies demonstrated only the single normal peak of LAP activity (Figure 3 ). A similar observation was made in two patients with common duct stone, who demonstrated a single normal peak of LAP activity after removal of the calculus (Figure 6). The disappearance of two peaks upon cure of these conditions also coincided with the fall of serum LAP to normal.

\section{DISCUSSION}

Leucine aminopeptidase activity of normal serum, measured at $\mathrm{pH} 7.1$, appears as a single peak with an electrophoretic mobility on starch gel which coincides with the postalbumin fraction of serum or the fast $\alpha_{2}$ and postalbumin fractions. Bile, pancreatic extract (Organon), and mixtures 
of these substances with normal serum likewise demonstrated a single peak of LAP activity similar to that found in normal serum.

The similarity of electrophoretic mobility of LAP from serum and bile and the histochemical localization of LAP in bile canaliculi (7) strongly suggest that these structures are the source of both serum and bile LAP which migrate with the postalbumin fraction or the fast $\alpha_{2}$ and postalbumin fractions. The possibility that the reverse is true, namely, that bile LAP is derived from serum, cannot be excluded.

The presence of two additional peaks of LAP activity in patients with either parenchymal or metastatic liver disease and their disappearance from the sera of those patients who have had clinical and biochemical recovery from infectious hepatitis and fatty infiltration of the liver is consistent with the possibility that LAP in the regions of origin to slow $\alpha_{2}$ and $\alpha_{2}$ to $\beta$-globulin is derived from the liver. However, their disappearance following relief of common bile duct obstruction, leaving the single normal peak, also indicates that stasis may alter LAP.

It is noteworthy that the electrophoretic mobility of serum LAP in two patients with carcinoma of the head of the pancreas was similar to that in normal subjects. Neither patient had jaundice or metastasis to the liver, and the total serum LAP activity in each was normal. In contrast, in patients with carcinoma of the head or body and tail of the pancreas who had either common duct obstruction or metastases to the liver, the serum LAP was elevated. Further, such patients demonstrated three peaks of LAP activity by starch gel electrophoresis. This finding is not specific for carcinoma of the pancreas since it was observed in four patients with carcinoma of the colon with metastases to the liver and in two patients with choledocholithiasis (Figures 4, 6).

These findings suggest that neither elevation nor electrophoretic alteration of serum LAP is specific for carcinoma of the pancreas; rather they support the hypothesis that such changes are dependent upon common bile duct obstruction or metastasis to the liver.

\section{SUMMARY}

1. The electrophoretic mobility of leucine aminopeptidase (LAP) of normal serum, sera of patients with pancreatic and hepatobiliary disease, bile, pleural fluid and pancreatic extract has been determined by starch gel electrophoresis.

2. There is a single peak of activity in normal serum identical with that of bile and pancreatic extract, located in the postalbumin fraction or in the fast $\alpha_{2}$ and postalbumin areas.

3. Two additional peaks of LAP activity are found in the sera of patients with parenchymal or metastatic liver disease and with common bile duct obstruction. With recovery of liver disease or relief of obstruction, these peaks disappear.

4. Electrophoretic mobility of serum LAP in patients with carcinoma of the pancreas is normal, unless there is common duct obstruction or metastasis to the liver.

\section{ACKNOWLEDGMENT}

The authors wish to acknowledge the assistance of Dr. Graham Jefferies and Mrs. Joan Freudenberger in the performance of the starch gel electrophoresis.

\section{REFERENCES}

1. Goldbarg, J. A., and Rutenburg, A. M. Colorimetric determination of leucine aminopeptidase in urine and serum of normal subjects and patients with cancer and other diseases. Cancer 1958, 11, 283.

2. Kowlessar, O. D., Haeffner, L. J., and Sleisenger, M. H. To be published.

3. Rutenburg, A. M., Goldbarg, J. A., and Pineda, E. P. Leucine aminopeptidase activity. Observations in patients with cancer of the pancreas and other diseases. New Engl. J. Med. 1958, 259, 469.

4. Smithies, O. Zone electrophoresis in starch gels: Group variations in the serum proteins of normal human adults. Biochem. J. 1955, 61, 629.

5. Pert, J. H., Sleisenger, M. H., Woods, K. R., and Engle, R. L., Jr. Requirements for optimal resolving power and reproducibility in protein fractionation by starch gel electrophoresis. Clin. Res. Proc. 1957, 5, 156.

6. Lowry, O. H., Rosebrough, M. J., Farr, A. L., and Randall, R. J. Protein measurement with the Folin phenol reagent. J. biol. Chem. 1951, 193, 265.

7. Nachlas, M. N., Crawford, D. T., and Seligman, A. M. Histochemical demonstration of leucine aminopeptidase. J. Histochem. Cytochem. 1957, 5, 264. 